\title{
Survey of Snuff Use and Preliminary Study of Effect of Two Brands on, Brain Antioxidants and Acetylcholinestrase Enzyme of Wister Albino Rats
}

\author{
Muhammad B.Yusuf ${ }^{1^{*}}$ PhD. Adamu R. Muhammad ${ }^{2}$ Pharm D. Zaruwa Z. Moses ${ }^{1}$ PhD. Ubaoji K. Ikechukwu ${ }^{3}$ \\ Ahmed M. Mustapha ${ }^{1}$ BSc.
}

\author{
* Corresponding Author: \\ Muhammad, B.Yusuf \\ rabbanimuhammad@yahoo.com
}

Received for publication July 08, 2020; Accepted April 26, 2021; Published online April 26, 2021.

\begin{abstract}
Copyright 2020 The Authors published by Al-Azhar University, Faculty of Medicine, Cairo, Egypt. All rights reserved. This an openaccess article distributed under the legal terms, where it is permissible to download and share the work provided it is properly cited. The work cannot be changed in any way or used commercially.
\end{abstract}

doi: $10.21608 /$ aimj.2021.35093.1274

${ }^{I}$ Department of Biochemistry and Molecular Biology, Faculty of Science, Nasarawa State University Keffi, Nigeria.

${ }^{2}$ Department of Pharmacy, Federal Medical Centre Keffi, Nigeria.

${ }^{3}$ Department of Applied Biochemistry, Nnamdi Azikiwe University, Awka, Anambra State, Nigeria.

\section{ABSTRACT}

Background: The use of snuff has resurfaced globally with an increasing trend among Nigerian populace.

Aim of the work: The research aimed to survey snuff use, effect of special moringa sundu (SMS) and smokeless tobacco (ST) on brain antioxidants and acetylcholinestrase (AchE) in vivo.

Material and Methods: 300 people were interviewed using questionnaire, on the consumption rate and effects of some snuff brands. Thereafter, 30 Wister albino rats $(110-120 \mathrm{~g})$ were randomly divided into five groups to investigate the effects of two brands in vivo. Group1 (control) received only distilled water daily. Groups 2 and 3 (received $6 \mathrm{mg}$ and $3 \mathrm{mg} / \mathrm{kg}$ b.w.t of ST respectively), groups 4 and 5 (received $6 \mathrm{mg}$ and $3 \mathrm{mg} / \mathrm{kg}$ b.w.t of SMS respectively). After two months, brains of all rats were isolated, homogenized and analyzed.

Result: Survey revealed that $70 \%$ use combination of different brands for sexual enhancement, $45 \%$ use SMS while $15 \%$ use ST for headache, vision, and itching. Animal studies revealed non-significant increase in SOD and GPx activities in groups 2, 3, and 4 compared to control, with concomitant increase in GSH levels. While a significant increase $(p<0.5)$ in MDA was detected in groups 2, 4 and 5. Brain AchE activity decreased significantly in both group 2 and 3 but increased significantly in group 4 and 5 compared to the control.

Conclusion: Oxidative stress is inhibited by SMS but induced by high dose ST while acetylcholinestrase activity is induced by SMS but inhibited by ST.

Keywords: Snuff; brain; antioxidants; acetycholinestrase enzyme.

Disclosure: The authors have no financial interest to declare in relation to the content of this article. The Article Processing Charge was paid for by the authors.

Authorship: All authors have a substantial contribution to the article. The conception and design writing of the first draft was done by Muhammad, B. Yusuf and Zaruwa, Z. Moses, acquisition of data by Ahmed, M. Mustapha, analysis and interpretation of data and revision of the article to obtain final draft was done by Adamu, R. Muhammad. Technical support, logistics and statistical analysis was handled by Ubaoji, I. Kingsley.

\section{INTRODUCTION}

Snuff is any product made from ground or pulverized tobacco leaves intended to be placed in the oral or nasal cavity. ${ }^{1}$ This distributes rapid nicotine sensation with long-lasting fragrance and essence. Snuff could be placed between lips and gum (moist snuff), or sniffed through the nose (dried powdered tobacco product). For instance "Naswar" a dipping smokeless tobacco product commonly used in Pakistan, Afghanistan, Iran and South Africa. ${ }^{2}$ Snuff became common in the United Kingdom throughout the seventeenth century, but powdered tobacco is documented to have been used by native inhabitants of Brazil before the coming of the Spaniards. ${ }^{3}$ In the western world, Snuff reemerged as substitutes, for tobacco and became generally acceptable among younger generations after the ban on smoking in many public places. The traditional snuff production involves the selection of varieties of tobacco leaves, 
tobacco, lion brand, Hajiyah Bilkisu, Hajiyah Fatima, Hajiyah Bilkisu Ma`a shaa Allah, Shehu Barhama, and Hajiyah Hauwa.

Recent studies suggested that long term use of smokeless tobacco could predispose to free radical generation and oxidative stress. ${ }^{5,6}$ Nicotine is a main bioactive component of tobacco. Previous studies have shown that low doses of nicotine can improve memory function and reduced plaque burden and could be used as anti-Alzheimer disease agent and improved attention performance in schizophrenia patients. ${ }^{7,8}$ However, some studies have indicated that nicotine impairs cognition in human and animal subjects. These inconsistencies could be attributed to the doses. It appears high dosage of nicotine might induce neurotoxicity. ${ }^{9}$ and excite oxidative stress, while low amount could improve cognitive performance. $^{8}$ On the other hand, the major component of the modern West African snuff is moringa oleifera a plant considered as one of the most beneficial trees in the world, with several medicinal, nutritional and industrial applications. ${ }^{10}$ 11 Moringa is rich in vitamins, antioxidants, $\beta$ carotene, amino acids, phenolics, and flavonoids. ${ }^{12}$ These various components of moringa make potent free radical scavengers, enzyme inhibitors, antioxidants, anti-bacterial, anti-tumor, cholesterol lowering, antipyretic, anti-inflammatory, antidiabetics' anti-ulcer among others. ${ }^{13}$

The rate of moringa snuff consumption has rampantly increased in Nigeria particularly the Northern region; where in the past, snuffing was considered to be filthy. The addiction to snuff is obvious, although the addicts claim that, it has various therapeutic benefits against different ailments. Unlike the "traditional snuff" (i.e. a blend of purely tobacco and flavouring agent) whose effect has been studied and documented to cause disorders such as cancer (of the mouth, lips, nasal cavities, oesophagus and gut), diabetes; hypercholesterolemia, myocardial infarction and teratogenicity, ${ }^{6}$ modern snuff contains high percentage of moringa beside other adjuncts and was never studied. For this reason, the current study aimed to survey some brands of snuff and the effect of special moringa sundu (SMS) and smokeless tobacco (ST) on brain antioxidants and acetylcholinestrase (AchE) in vivo.

\section{MATERIAL AND METHODS}

\section{Chemicals and kits}

The chemicals used in this research include disodium hydrogen phosphate $\left(\mathrm{Na}_{2} \mathrm{HPO}_{4}\right)$, sodium dihydrogen phosphate $\left(\mathrm{NaH}_{2} \mathrm{PO}_{4}\right)$ sodium chloride $(\mathrm{NaCl})$ and ethanol $95 \%$ and isoflurane were purchased from Fluka, Switzerland. All kits used where obtained from Solarbios Life Science Limited, Beijing China. These include Superoxide dismutase (SOD) Catalog Number: BC0175, Glutathione Peroxidase (GPX) Catalog Number: BC0174, Malondialdehyde (MDA) Catalog Number: BC002, reduced glutathione (GSH) Catalog Number: BC1175), Acetylcholinesterase (AchE) Assay Kit Catalog Number: BC2020

\section{Snuff samples, composition and preparation}

The products figure 1 (smokeless tobacco and special moringa sundu) were purchased from retail shop in keffi town, Nasarawa State, Nigeria. Based on manufacturer's description, Smokeless tobacco contains ground tobacco leaves and menthol while special moringa sundu contains tobacco powder, menthol and moringa powder.

To prepare snuff solution; $1 \mathrm{~g}$ of sample was dissolved in 1 liter of deionized water and refrigerated until used.

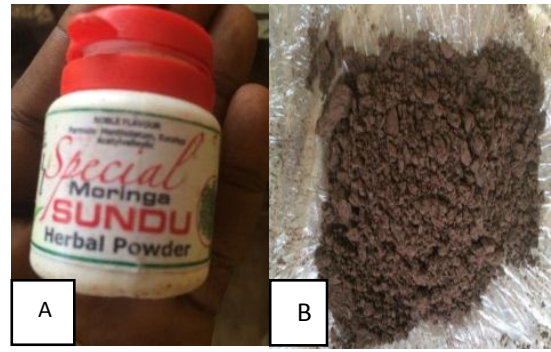

Fig. 1: Snuff samples: A. Special Moringa Sundu; B. Smokeless Tobacco

A: Commercial product containing a mixture of moringa powder, tobacco powder and menthol

B: Commercial product containing finely pulverized dried tobacco leaves with neither sweetener nor flavourings

\section{Experimental Design:}

The study was carried out in two phases. The first phase involved the use of questionnaire to obtain relevant information from snuff users. This provided an insight into the average quantity of each snuff consumed and also the reward-seeking behavior of the users.

The second phase i.e. the in vivo study in rats which was approved by the Nasarawa State University Keffi Animal Ethics Committee, involved the use of smokeless tobacco, special moringa sundu, and thirty (30) Wister albino rats (weighing 110-120g). The snuffs were obtained from shop number nine (9) Kaduna road Angwan NTA keffi, Nasarawa state; the antioxidant and acetyl cholinesterase enzyme kit used were obtained from Solarbios Life Science Limited, Beijing China while the rats were obtained from National veterinary research institute (NVRI) VOM, Plateau state.

These rats were housed in cleaned plastic cages, bedded with clean rice husks, a 12 hour light: 12 hour dark cycle and free access to food and water ad libitum. After two (2) weeks acclimation period, the animals were weighed and randomized into five (5) designated groups of six (6) rats each: Group 1 (control received no treatment), Group 2 (received a dose of $6 \mathrm{mg} / \mathrm{Kg}$ body weight smokeless tobacco), Group3 (received a dose of $3 \mathrm{mg} / \mathrm{Kg}$ body weight smokeless tobacco), Group4 (received a dose of 
$6 \mathrm{mg} / \mathrm{Kg}$ body weight special moringa sundu), and Group5 (received a dose of $3 \mathrm{mg} / \mathrm{Kg}$ body weight special moringa sundu)

All animals received humane treatment; they were fed with growers mesh and allowed access to water throughout the treatment period (two months). Food gavage was used in the administration of the solution.

At the end of the experiment (administering of snuff solution) rats were weighed, sedated using $5 \% \mathrm{~V} / \mathrm{v}$ isoflurane and oxygen $1.5 \mathrm{~L} / \mathrm{min}$ flow, the skulls were dissected quickly and the brain tissues were quickly removed and washed in phosphate buffer solution of $\mathrm{pH}$ 7.4. The brain tissues were instantly placed in ice and refrigerated at $-20^{\circ} \mathrm{C}$ for $24 \mathrm{hrs}$.

\section{Preparation of Brain homogenate}

Brain tissues were cut into pieces, weighed and two (2g) grams was homogenized in 20 volumes of phosphate buffer saline $\mathrm{pH} 7.4(0.1 \mathrm{M})$, at $700 \mathrm{~g}$ in ice for $10 \mathrm{~min}$, then centrifuged for $15 \mathrm{~min}$ at 5000 $\mathrm{rpm}$. The supernatant was then collected and stored at $-20{ }^{\circ} \mathrm{C}$ until use. ${ }^{14}$

Biochemical analysis

Determination of superoxide dismutase (SOD) Activity

SOD activities were determined colorimetrically according to manufacturer's (Solarbios Life Science) instructions. SOD catalyzes the conversion of superoxide molecules $\left(\mathrm{O}_{2}^{-)}\right.$into either molecular oxygen $\left(\mathrm{O}_{2}\right)$ or hydrogen peroxide $\left(\mathrm{H}_{2} \mathrm{O}_{2}\right)$. The $\mathrm{O}_{2}$ reduces nitro-blue tetrazolium to form blue formazan, which absorbs at $560 \mathrm{~nm}$. SOD reacts with $\mathrm{O}_{2}{ }^{-}$and suppresses the blue reaction. The intensity of the blue color is inversely proportional to the SOD activity. ${ }^{15}$

\section{Glutathione Peroxidase (GPx) Activity}

The Glutathione Peroxidase Activity Assay kit was used to measure glutathione peroxidase in the tissue extracts according to manufacturer's protocol. The assay is based on the oxidation of reduced glutathione (GSH) to oxidized glutathione (GSSG) which is catalyzed by GPx In the presence of GSH, glutathione reductase and NADPH. Glutathione peroxidase activity corresponds to oxidation of NADPH to NADP. Absorbance was measured at 340 $\mathrm{nm}^{16}$

\section{Determination of total reduced glutathione (GSH)}

Glutathione (GSH) is a natural three peptide containing sulfhydryl (SH). It is composed of glutamic acid, cysteine and glycine; it Glutathione react with 5,5'-dithiobis-2-nitrobenoic acid (DTNB) to give a yellow product that absorbs maximum ally at $412 \mathrm{~nm}$. The amount of GSH was determined as $\mathrm{GSH}\left(\mu \mathrm{g} / \mathrm{g}\right.$ tissue). ${ }^{17}$

\section{Determination of Malondialdehyde (MDA) level}

Malondialdehyde (MDA) is one of the convenient markers of lipid peroxidation. At an acidic $\mathrm{pH}$ and high temperature, MDA and thiobarbituric acid
(TBA) condenses to form brown red 3,5,5- three methyl sulfamethoxazole -2,4-two ketone with largest absorption wavelength of $532 \mathrm{~nm}$. The level of MDA was calculated by the difference between the absorbance at $532 \mathrm{~nm}, 450 \mathrm{~nm}$ and $600 \mathrm{~nm}$ as instructed by the kit's manufacturer. ${ }^{18}$

\section{Determination of acetylcholinesterase (AchE) Activity}

AchE catalyzes Ach hydrolysis to generate choline, and choline reacts with 5,5'-dithiobis(2-nitrobenzoic acid) to form 5-mercapto nitrobenzoic acid (TNB) which absorbs at at $412 \mathrm{~nm}$. AchE activity was expressed as $\mathrm{U} / \mathrm{g}$ tissue as described by the kit manufacturers. 19

\section{RESULTS}

The result in table1 revealed the response of 300 active snuff users. $70 \%$ use combination of different brands for sexual enhancement while $40 \%$ use Special moringa sundu (SMS) for sexual enhancement. $45 \%$ claimed SMS relieves headache, improves vision, and relieves itching, while $15 \%$ claimed Smokeless tobacco (ST) relieves eye itching, fever and tooth ache. SMS comes in $16 \mathrm{~g}$ container while ST comes in $14 \mathrm{~g}$ container. From the data obtained, $75 \%$ of users finish a container in two weeks, $15 \%$ in three weeks and $10 \%$ in four weeks irrespective of the brand.

$\mathbf{L D}_{50}$ Determination of different snuff products.

The results of the acute toxicity studies of various snuff products showed mild toxicity, such as difficulty in breathing, shivering, tremors, anxiety and aggressive behavior. The $\mathrm{LD}_{50}$ was estimated to be $2750 \mathrm{mg} / \mathrm{kg}$ body weight and $2800 \mathrm{mg} / \mathrm{kg}$ body weight for special moringa sundu and smokeless tobacco respectively.

The result revealed a non-significant $(\mathrm{P}>0.05)$ decrease in SOD and GPx activities in all treatment groups with concomitant increase in GSH levels when compared to the control. On the contrary, a significant $(\mathrm{P}<0.05)$ increase in MDA level was observed in groups 3, 4 and 5 while group 2 showed a decrease. Furthermore, the AchE activity decreased significantly $(\mathrm{P}<0.05)$ in both groups 2 and 3 but increased in group 4 and 5 significantly, when compared to the control. 
PARAMETER

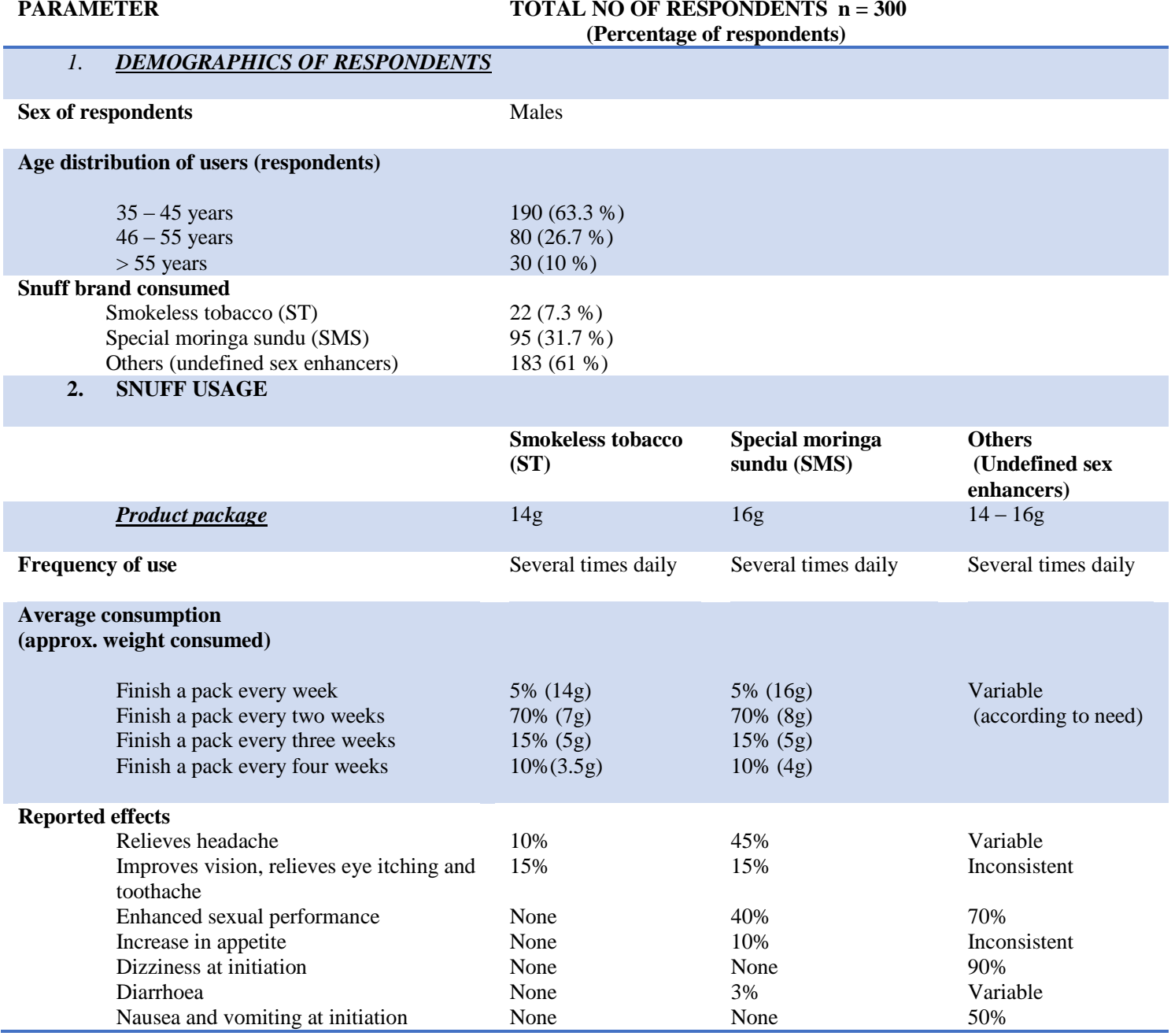

Table 1: Survey of some Snuff Brands commonly consumed in Nigeria. The results in table1 revealed about 300 people were interviewed through a questionnaire, on the consumption rate/doses, effects experiences and the two brands consumed.

\begin{tabular}{|c|c|c|c|c|c|}
\hline GROUP & $\begin{array}{l}\text { SOD } \\
\text { (U/g tissue) }\end{array}$ & $\begin{array}{l}\text { GSH } \\
(\mu \mathrm{g} / \mathrm{g} \text { tissue })\end{array}$ & $\begin{array}{l}\text { GPx } \\
\text { (U/g tissue ) }\end{array}$ & $\begin{array}{l}\text { MDA } \\
\text { (nmol/g tissue ) }\end{array}$ & $\begin{array}{l}\text { AchE } \\
\text { (U/g tissue ) }\end{array}$ \\
\hline $\begin{array}{l}\text { GP1 } \\
\text { (Control) }\end{array}$ & $68.37 \pm 4.14^{\mathrm{a}}$ & $55.13 \pm 6.49^{\mathrm{a}}$ & $39.61 \pm 5.33^{\mathrm{a}}$ & $17.42 \pm 4.41^{\mathrm{a}}$ & $28.05 \pm 6.23^{\mathrm{a}}$ \\
\hline GP2 (ST-HD & $61.46 \pm 11.32^{\mathrm{ab}}$ & $91.66 \pm 6.98^{\mathrm{ab}}$ & $36.20 \pm 3.80^{\mathrm{ab}}$ & $21.93 \pm 1.01^{\mathrm{ab}}$ & $13.81 \pm 2.30^{\mathrm{b}}$ \\
\hline $\begin{array}{l}\text { GP3 } \\
\text { ( ST-LD) }\end{array}$ & $61.92 \pm 2.59^{\mathrm{ab}}$ & $64.07 \pm 3.58^{\mathrm{ab}}$ & $34.81 \pm 3.32^{\mathrm{ab}}$ & $27.35 \pm 7.03^{c}$ & $15.20 \pm 4.53^{\mathrm{b}}$ \\
\hline $\begin{array}{l}\text { GP4 } \\
\text { (SMS-HD) }\end{array}$ & $49.55 \pm 4.35^{\mathrm{c}}$ & $341.59 \pm 70.78^{c}$ & $20.16 \pm 2.16^{c}$ & $13.26 \pm 3.10^{\mathrm{ad}}$ & $48.19 \pm 11.59^{c}$ \\
\hline $\begin{array}{l}\text { GPD } \\
\text { (SMS-LD) }\end{array}$ & $28.63 \pm 3.16^{\mathrm{d}}$ & $503.29 \pm 108.07^{d}$ & $16.32 \pm 2.23^{\mathrm{d}}$ & $3.43 \pm 1.40^{\mathrm{e}}$ & $39.00 \pm 5.64^{\mathrm{d}}$ \\
\hline
\end{tabular}

Table 2: Effect of Snuff on Brain Levels of SOD, GPx, GSH, MDA and AchE Activity of Wister Albino Rats. Results are expressed as Mean $\pm \mathrm{SD}, \mathrm{n}=6$ values in each column having different superscript $(\mathrm{a}, \mathrm{b}, \mathrm{c}, \mathrm{d}, \mathrm{e})$ are significantly different at $\mathrm{p}<0.05$. GP $=$ Group, $\mathrm{ST}=$ smokeless tobacco, $\mathrm{SMS}=$ special moringa sundu.

\section{DISCUSSION}

The snuff users uninterruptedly use the various products for different motives especially for sexual enhancement. Other reasons include better vision, fever, headache, itching among others. Similar scenarios have been reported among men in the US, Scandinavia and particularly in Sweden, where approximately $20 \%$ of men snuffle on daily basis.
This addiction could be attributed to the tobacco powder and menthol usually added in all brands of snuff. $^{20}$ While tobacco contains nicotine whose addiction had been documented, menthol which is also incorporated in the snuff was found to potentiate tobacco addiction through biological mechanisms ${ }^{21}$ which include; alteration of nicotinic receptors, 
masking of tobacco aversive behaviours and increasing nicotine bioavailability. ${ }^{22,}{ }^{23}$ Although users derive some therapeutic benefit, in most cases it has just become a habit, synonymous to smoking cigarette or eating kola nut. Finally if the users actually snuffle for the acclaimed therapeutic benefits, then it is expected that they should cease to continue when the ailment is cured, but they persist.

The brain is an important part of the biological system whose function helps to regulate other parts of the body. However, any injury or form of stress experienced in this organ may have severe influence on the entire organism. Several studies have shown that the mechanism of snuff action in animals is associated with production of reactive oxygen species (ROS). ${ }^{5,6,12,24}$

SOD detoxifies superoxide radicals to hydrogen peroxide, which can be further detoxified to water by GPx. In this study, all groups showed an increase in MDA and GSH levels with simultaneous decrease in SOD and GPx activities. This is similar to previous studies which revealed decrease in SOD, GPx and catalase in "Maras" powder (a product that contains smokeless tobacco) users. ${ }^{24}$ It indicates that tobaccos induces reactive oxygen species (ROS) generation and inhibit antioxidant enzymes activities at the same time. ROS can interact with cellular biomolecules principally lipids, to generate MDA and other lipids peroxide. These lipid peroxides can interact with different proteins such as enzymes to interfere with their active site thus their activities. ${ }^{25}$ On the other hand in groups 4 and 5, SOD, GPx and MDA decreased drastically with concomitant increase in GSH level. Strangely, this could be attributed to the low concentration of substrate (superoxide radical) for SOD due to the free radical scavenging and antioxidant activities of moringa oleifera found in the SMS snuff. It has been established that moringa is a rich source of vitamins, amino acids and polyphenols and flavonoids. ${ }^{12,}{ }^{26}$ It is likely that the amino acids contribute to the GSH pool and the vitamins provide coenzymes for synthesis of GSH. ${ }^{27}$ Furthermore, the polyphenols and flavonoids could have scavenged the free radicals generated either denovo or by the metabolism of little tobacco additive in the snuff. ${ }^{28}$ Conversely, the acetyl cholinesterase enzyme (AchE) activities in groups administered with smokeless tobacco (2 and 3 ) decreased drastically, which could improve cognitive function due to nicotine content. ${ }^{29}$ Ach is one of the central neurotransmitter, which plays a significant role in memory, learning and cognition. ${ }^{30}$ It relays signal from one neuron to another in the central nervous system and from neuron to muscle fiber in the peripheral nervous system. AchE is the enzyme that breaks acetylcholine to the choline and acetate. ${ }^{30}$ Inhibition or decrease in AchE activities increases the concentration of Ach at the synaptic junction and allows for potentiation of the signal. ${ }^{31}$ This would eventually reduce the amount of choline uptake and increase the number of nicotinic receptors; which in turn will boost memory, learning and cognition in snuff users. ${ }^{32}$ Similarly the snuff contains menthol which has been reported to potentiate and promote binding of nicotine to nicotinic receptors (nAChRs) which is an agonist of acetylcholine. ${ }^{33}$

Conversely, rats administered special moringa sundu snuff (group 4 and 5) showed a two fold increase in AchE activity which can lead to a decrease in the concentration of Ach at the synaptic junction and consequently, a decreased cholinergic activity. This result differs from previous research which reported that pure moringa oleifera water extract inhibit AchE activity. ${ }^{34}$ This means that although the moringa sundu snuff decreased lipid peroxidation and improved GSH level, it could however, decrease alertness and cognitive function. ${ }^{35}$

\section{CONCLUSION}

Although Smokeless tobacco induces oxidative stress at high concentration, low dose could improve cognitive function through inhibition of acetyl cholinesterase enzyme activity. However, Special moringa sundu decreased lipid peroxidation and increased reduced glutathione level, but also increased acetyl cholinesterase enzyme activity which would cause decline in cognitive function as a result of the decreased acetylcholine pool. These could suggest that combination of moringa and tobacco would yield better snuff.

\section{ACKNOWLEDGEMENT}

We acknowledge the contribution of Mal. Aliyu of the central Lab Department of Biochemistry Ahmadu Bellow University Zaria Nigeria.

\section{REFERENCES}

1. Odangowei O, Tobia P-E and Adigwe P. Microbial contamination of snuff sold in selected markets in Yenagoa, Bayelsa State, Nigeria. 2018;3:2455-4227.

2. Sajid F and Bano S. Effects of smokeless dipping tobacco (Naswar) consumption on antioxidant enzymes and lipid profile in its users. Pakistan journal of pharmaceutical sciences 2015;28:1829-33.

3. Khan Z, Suliankatchi RA, Heise TL, et al. Naswar (Smokeless Tobacco) Use and the Risk of Oral Cancer in Pakistan: A Systematic Review With Meta-Analysis. Nicotine \& Tobacco Research 2017;21:32-40.

4. Muhammad-Kah RS, Pithawalla YB, Boone EL, et al. A Computational Model for Assessing the Population Health Impact of Introducing a Modified Risk Claim on an Existing Smokeless Tobacco Product. International journal of environmental research and public health 2019;16:1264.

5. Constance J, Lusher JM and Murray E. The use of smokeless tobacco among UK South Asian communities. MOJ Addiction Medicine and Therapy 2019;6:49-53. 
6. Avti PK, Kumar S, Pathak CM, et al. Smokeless tobacco impairs the antioxidant defense in liver, lung, and kidney of rats. Toxicological Sciences 2005;89:547-53.

7. Barr RS, Culhane MA, Jubelt LE, et al. The effects of transdermal nicotine on cognition in nonsmokers with schizophrenia and nonpsychiatric Neuropsychopharmacology 2008;33:480.

8. Swan GE and Lessov-Schlaggar CN. The Effects of Tobacco Smoke and Nicotine on Cognition and the Brain. Neuropsychology Review 2007;17:259-73.

9. Gupta R, Gupta S, Sharma S, et al. Association of smokeless tobacco and cerebrovascular accident: a systematic review and metaanalysis of global data. J Public Health (Oxf) 2020;42:e150-e157.

10. Saini RK, Sivanesan I and Keum Y-S. Phytochemicals of Moringa oleifera: a review of their nutritional, therapeutic and industrial significance. 3 Biotech 2016;6:203.

11. Desale T. Nutritional and Medicinal Importance of Moringa Oliefera. 2019;6:1-5.

12. Saleem A, Saleem M, Akhtar MF, et al. Moringa rivae leaf extracts attenuate Complete Freund's adjuvant-induced arthritis in Wistar rats via modulation of inflammatory and oxidative stress biomarkers. Inflammopharmacology 2019:1-13.

13. Atta AH, Mouneir SM, Nasr SM, et al. Phytochemical studies and anti-ulcerative colitis effect of Moringa oleifera seeds and Egyptian propolis methanol extracts in a rat model. Asian Pacific Journal of Tropical Biomedicine 2019;9:98.

14. Bawa Yusuf M, Nadia Zaky S, Fatima Hassan E, et al. Antioxidant, Anti-inflammatory, Antiproliferative and Antimicrobial Activities of Combretum glutinosum and Gardenia aqualla Extracts in vitro. Free Radicals and Antioxidants 2019;9:66-72.

15. Marklund SL. Extracellular superoxide dismutase and other superoxide dismutase isoenzymes in tissues from nine mammalian species. Biochemical Journal 1984;222:64955.

16. Paglia DE, Konrad PN, Wolff JA, et al. Biphasic reaction kinetics in an anomalous isozyme of erythrocyte pyruvate kinase. Clinica Chimica Acta 1976;73:395-405.
17. Jollow DJ, Mitchell JR, Zampaglione N, et al. Bromobenzene-Induced Liver Necrosis. Protective Role of Glutathione and Evidence for 3,4-Bromobenzene Oxide as the Hepatotoxic Metabolite. Pharmacology 1974;11:151-69.

18. Ohkawa H, Ohishi $\mathrm{N}$ and Yagi K. Assay for lipid peroxides in animal tissues by thiobarbituric acid reaction. Anal Biochem 1979;95:351-8.

19. Hiroaki O, Kazuyo S, Nobuyuki N, et al. New enzymatic assay of cholinesterase activity. Clinica Chimica Acta 1977;80:87-94.

20. Addicott MA. Chapter 9 - Tobacco addiction: cognition, reinforcement, and mood. In: Verdejo-Garcia A, ed. Cognition and Addiction: Academic Press, 2020:129-41.

21. Wickham RJ. How Menthol Alters TobaccoSmoking Behavior: A Biological Perspective. The Yale journal of biology and medicine 2015;88:279-87.

22. Wickham RJ. The biological impact of menthol on tobacco dependence. Nicotine Tob Res 2019.

23. Henderson BJ. Chapter 12 - Linking Nicotine, Menthol, and Brain Changes. In: Preedy VR, ed. Neuroscience of Nicotine: Academic Press, 2019:87-95.

24. Kilinc M, Okur E, Kurutas EB, et al. The effects of Maras powder (smokeless tobacco) on oxidative stress in users. Cell Biochemistry and Function: Cellular biochemistry and its modulation by active agents or disease 2004; 22:233-6.

25. Muhammad BY, Shaban NZ, Elrashidy FH, et al. Anti-Oxidant, Anti-Inflammatory, AntiProliferative and Anti-Microbial Activities of Combretum glutinosum and Gardenia aqualla extracts in vitro. 2019

26. Bancessi A, Bancessi Q, Baldé A, et al. Present and potential uses of Moringa oleifera as a multipurpose plant in Guinea-Bissau. South African Journal of Botany 2019.

27. Huang C and Yin Z. Highly Efficient Synthesis of Glutathione via a Genetic Engineering Enzymatic Method Coupled with Yeast ATP Generation. Catalysts 2020;10:33.

28. Tripathi P, Alshahrani S, Alhazmi HA, et al. In vivo assessment of genotoxic potential of brown shammah (smokeless tobacco) in bone marrow cells of mice. Saudi Pharmaceutical Journal 2020;28:480-6. 
29. Bhattacharya D, Fujihashi A, Majrashi M, et al. Concurrent nicotine exposure to prenatal alcohol consumption alters the hippocampal and cortical neurotoxicity. Heliyon 2020; 6:e03045

30. Baxter MG and Crimins JL. Acetylcholine Receptor Stimulation for Cognitive Enhancement: Better the Devil You Know? Neuron 2018;98:1064-6.

31. Colović MB, Krstić DZ, Lazarević-Pašti TD, et al. Acetylcholinesterase inhibitors: pharmacology and toxicology. Current neuropharmacology 2013;11:315-35.

32. Trang A and Khandhar PB. Physiology, Acetylcholinesterase. StatPearls [Internet]: StatPearls Publishing, 2019.
33. Shahoei $\mathrm{R}$ and Tajkhorshid E. Menthol Binding to the Human $\alpha 4 \beta 2$ Nicotinic Acetylcholine Receptor Facilitated by Its Strong Partitioning in the Membrane. The Journal of Physical Chemistry B 2020; 124: 1866-80.

34. Sriraksa N. Effects of Moringa oleifera on the Acetylcholinesterase and Monoamine Oxidase Activities in the Streptozotocin-Induced Diabetic Rat Brains. Naresuan Phayao Journal 2019;12:13-22.

35. Gustav K, Eli G, Yakubu J, et al. Phytochemistry, proximate and antioxidant properties of some indigenous leafy vegetables. World Journal of Advanced Research and Reviews 2019;3:012-022. 